\title{
Incidence of Cardiac Injury and Associated Poor Outcomes in Hospitalized Patients with COVID-19: A Systematic Review and Meta-Analysis
}

Fengwei Zou ( $\square$ fz90@georgetown.edu )

Georgetown University School of Medicine

Zhiyong Qian

the First Affiliated Hospital of Nanjing Medical University

\section{Systematic Review}

Keywords: COVID-19, cardiac injury, meta-analysis, systemic review

Posted Date: April 23rd, 2020

DOI: https://doi.org/10.21203/rs.3.rs-24567/v1

License: (c) (i) This work is licensed under a Creative Commons Attribution 4.0 International License.

Read Full License 


\section{Abstract}

Background: Increasing number of studies have indicated a link between coronavirus disease 2019 (COVID-19) and acute cardiac injury. However, there is currently no consensus on the incidence of cardiac injury and its associated prognosis in COVID-19 patients.

Methods: We searched PubMed and Embase for studies that evaluated cardiac injury in hospitalized COVID-19 patients. Demographic information, co-morbidities, and relevant laboratory values were extracted and a meta-analysis was performed.

Results: Ten studies with 1637 patients were included in this meta-analysis. The overall incidence of cardiac injury was $23.2 \%$ (380/1637) in hospitalized COVID-19 patients. The incidence was higher (58.5\%) in patients who were critically ill, admitted to the intensive care unit (ICU) or died. The composite mortality rate of patients with cardiac injury was $75.1 \%$ (251/334). Cardiac injury was significantly associated with increased mortality $(\mathrm{OR}=21.71,95 \% \mathrm{Cl}$ 9.16-51.46) in those patients. When combining death with ICU admission and patients who were critically ill, patients with cardiac injury was again strongly associated with worse outcomes (OR=22.18, 95\% $\mathrm{Cl} 11.68-42.10)$. In subgroup analyses, hospitalized COVID-19 patients who were older and had history of hypertension, coronary artery disease, chronic obstructive respiratory disease, and diabetes were associated with increased risk of developing cardiac injury.

Conclusion: Cardiac injury is common in hospitalized COVID-19 patients and is significantly associated with poor outcomes. Patients who are older and have hypertension, diabetes, coronary artery diseases and chronic obstructive pulmonary diseases are prone to develop cardiac injury. When appropriate, early screening, triage and cardiac monitoring are needed for these patients.

\section{Introduction}

Coronavirus disease 2019 (COVID-19) is caused by severe acute respiratory syndrome coronavirus 2 (SARS-CoV-2) and is the most recently discovered member of the coronavirus family. Since late December 2019, COVID -19 has caused initially a local epidemic in Wuhan, China and subsequently a global pandemic involving 212 countries, areas or territories. As of April 11, 2020, more than 160,000 cases have been confirmed and 99,000 lives lost[1]. As we gradually came to understand that this virus is not simply one that causes respiratory symptoms, more and more cases and reports have shown alarming complications in the cardiovascular system. Recent works by Huang et al[2] and Guo et al[3] not only demonstrated that a considerable number of hospitalized patients diagnosed with COVID-19 exhibited cardiac injury (represented by elevation of cardiac biomarkers such as troponin), but that those who developed cardiac injury had a significantly higher mortality than those without. Moreover, Shi et al[4] performed a multivariate analysis of 416 patients and found that cardiac injury was independently associated with an increased risk of mortality in patients with COVID-19. Despite these illuminating results, few other studies directly looked into the association of cardiac injury with prognosis and co- 
morbidities. As a result, the authors have decided to perform a systematic review and meta-analysis to further investigate the correlation between cardiac injury and outcomes in COVID-19 patients.

\section{Methods}

\section{Data Source and Searches}

We performed a systematic literature search in PubMed and Embase. We used the search term "coronavirus". The search was limited to Chinese and English and all articles from Jan 1, 2020 to April 5, 2020 were reviewed.

\section{Study Selection, Data Extraction and Definitions}

Original studies that reported cardiac injury, troponin or creatine kinase MB (CKMB) were included. Review articles, meta-analysis and case reports were excluded. The extracted data included the number of patients enrolled in each study, age, gender, co-morbidities (coronary artery disease [CAD], diabetes [DM], hypertension [HTN], and chronic obstructive pulmonary diseases [COPD]), laboratory values (C-reactive protein [CRP], procalcitonin, and NT-pro brain natriuretic peptide [NT-proBNP]), and mortality. Definitions of cardiac injury for each article were reviewed and all studies defined cardiac injury as troponin above the $99^{\text {th }}$ percentile upper limit of the reference range.

In studies that did not directly report mortality in patients with or without cardiac injury, the mortality of patients with cardiac injury was calculated as the ratio of deceased patients with cardiac injury over all patients with cardiac injury. Poor outcomes were defined as a composite of death, intensive care unit (ICU) admission and those reported as "critically ill" by the original authors (Chen C. et al and Zhou B. et al) per the Diagnosis and Treatment Protocol for Novel Coronavirus Pneumonia $6^{\text {th }}$ Edition, National Health Commission of the People's Republic of China (abbreviated as the $6^{\text {th }}$ edition)[5]. It was defined as patients who fit into any one of the following: 1) respiratory failure in need of mechanical ventilation; 2 ) shock; or 3) other organ dysfunction needing ICU admission[5].

\section{Statistical analysis}

Review Manager 5.3 (Cochrane, London, UK) was used to perform data analysis. Continuous data were extracted and median with interquartile range was converted to mean with standard deviation using the equations delineated by Hozo et al[6]. Dichotomous variables were analyzed using the Mantel-Haenszel method and the random effects model. A 95\% confidence interval was selected and the results were expressed as odds ratio. $P$ value of less than 0.05 was considered statistically significant. Statistical heterogeneity was evaluated using the $\mathrm{I}^{2}$ statistic. Publication bias was evaluated using funnel plots.

\section{Results}




\section{Study characteristics}

A total of 2413 abstracts resulted with the search term as of April 5, 2020. Each abstract was reviewed by the authors and 48 studies that reported troponin and CKMB were reviewed in full. Figure 1 shows the literature search and selection process. Since most early data originated from Wuhan, China, several original articles included patients from the same hospitals during the same period of time. Only the ones with more patients were included in the analysis to minimize duplication and maximize study effect. He et al[7] had a different definition of cardiac injury ( $>3$ times the reference value of troponin) and was not included in the final analysis. The study by Du et al[8] was an observational study that only reported fatal cases and was also not included. As a result, 10 studies were included in the analysis and these studies were summarized in Table 1.

\section{Incidence, mortality and poor outcomes of hospitalized COVID-19 patients with cardiac injury}

The pooled overall incidence of cardiac injury in hospitalized COVID-19 patients was $23.2 \%(380 / 1637)$. We separately calculated the incidence of cardiac injury in hospitalized COVID-19 patients who were in the poor outcomes category defined above. The incidence of cardiac injury for those patients was $58.5 \%$ (286/489). In contrast, the incidence of cardiac injury in patients who were not in the poor outcomes group was only $8.3 \%$ (95/1148). Supplemental Table 1 compiles the incidence of cardiac injury in hospitalized COVID-19 patients.

The overall mortality rate of hospitalized COVID-19 patients with cardiac injury was $75.1 \%(251 / 334)$. Compared to patients without cardiac injury, these patients had significantly higher risk for mortality (OR $=21.71,95 \% \mathrm{Cl} 9.16-51.46, \mathrm{I}^{2}=75 \%, \mathrm{Z}=6.99, \mathrm{P}<0.00001$ ) as shown in Figure $2 \mathrm{~A}$.

The overall rate of poor outcomes in hospitalized COVID-19 patients with cardiac injury was $75.3 \%$ (286/380). A comparison of poor outcomes between patients with or without cardiac injury also revealed significantly higher odds of poor outcomes in those with cardiac injury $(O R=22.18,95 \% \mathrm{Cl} 11.68-42.10$, $\left.\mathrm{I}^{2}=61 \%, \mathrm{Z}=9.48, \mathrm{P}<0.00001\right)$ as shown in Figure 2B. Funnel plots in Supplemental Figure 1 showed symmetrical distribution of effect sizes in the studies included in the mortality and poor outcomes analysis.

\section{Demographics/Co-morbidities and Cardiac Injury}

Combining data from the two papers that directly compared patients with or without cardiac injury, we found that patients with cardiac injury were of older age (mean difference $=15.98$ years, $95 \% \mathrm{Cl} 11.80-$ $\left.20.15, \mathrm{I}^{2}=74 \%, \mathrm{Z}=7.50, \mathrm{P}<0.00001\right)$ and consisted of fewer females $\left(\mathrm{OR}=0.58,95 \% \mathrm{Cl} 0.28-1.18, \mathrm{I}^{2}=\right.$ $67 \%, Z=1.50, P=0.13$ ). However, the gender discrepancy was not statistically significant (Figure 4A-B). 
Hospitalized COVID-19 patients who had a history of HTN (OR $=5.13,95 \% \mathrm{Cl} 3.41-7.72, \mathrm{I}^{2}=0 \%, \mathrm{Z}=$ $7.84, P<0.00001), C A D\left(O R=8.94,95 \% \mathrm{Cl} 3.83-20.87, \mathrm{I}^{2}=44 \%, Z=5.07, P<0.00001\right), D M(O R=3.07$, $\left.95 \% \mathrm{Cl} 1.64-5.75, \mathrm{I}^{2}=35 \%, \mathrm{Z}=3.51, \mathrm{P}=0.0004\right)$ and $\mathrm{COPD}\left(\mathrm{OR}=6.33,95 \% \mathrm{Cl} 1.44-27.85, \mathrm{I}^{2}=23 \%, \mathrm{Z}=\right.$ $2.44, \mathrm{P}=0.01)$ all had significantly increased risk of developing cardiac injury during hospitalization (Figure 4C-F).

\section{Cardiac Injury and lab values}

Last but not least, we looked into the correlation of important laboratory parameters and cardiac injury (Figure 5A-C). Hospitalized COVID-19 patients with cardiac injury had significantly higher CRP (mean difference $=6.00,95 \% \mathrm{Cl} 4.95-7.06, \mathrm{I}^{2}=85 \%, \mathrm{Z}=11.15, \mathrm{P}<0.00001$ ), procalcitonin (mean difference $=$ $0.18,95 \% \mathrm{Cl} 0.13-0.23, \mathrm{I}^{2}=76 \%, \mathrm{Z}=7.33, \mathrm{P}<0.00001$ ) and NT-proBNP (mean difference $=1113.44,95 \%$ $\mathrm{Cl} 256.94-1969.95, \mathrm{I}^{2}=99 \%, Z=2.55, \mathrm{P}=0.01$ ) levels.

\section{Discussion}

Our meta-analysis of the currently published data has demonstrated that: 1) a considerable amount of hospitalized COVID-19 patients developed cardiac injury (23.2\%) and the incidence was significantly higher in patients who were sicker $(58.5 \%)$; 2 ) hospitalized COVID-19 who developed cardiac injury exhibited significantly higher rates of mortality $(75.1 \%)$ and poor outcomes $(75.3 \%)$ compared to those without; and 3) hospitalized COVID-19 patients who were older and had co-morbidities including HTN, CAD, DM and COPD demonstrated increased risk of developing cardiac injury.

\section{Incidence of cardiac injury in COVID-19 patients}

Since the outbreak in China, increasing spotlight has been brought up on cardiac injury in COVID-19 patients who needed inpatient care. Hu et al[9] described a 37 year-old male patient in Wuhan positive for COVID-19 who developed fulminant myocarditis after three days of chest pain and shortness of breath. He presented with hemodynamic instability, severely elevated cardiac biomarkers (Troponin T [TnT] $>10,000 \mathrm{ng} / \mathrm{L}$ and NT-BNP >21,000 ng/L) and depressed ventricular systolic function (LVEF 27\%). In Europe, Inciardi et al[10] reported an otherwise healthy 53 year-old female positive for COVID-19 who developed acute myopericaridits. Similarly, she had elevated cardiac biomarkers as well as radiographic evidence of biventricular myocardial interstitial edema and diffuse late gadolinium enhancement on cardiac magnetic resonance imaging. Fortunately, both patients stabilized after undergoing aggressive treatment. These case reports should ring a bell on the potential involvement of the cardiovascular system in a wider range of COVID-19 patients worldwide.

More than a dozen studies have reported incidence of cardiac injury in hospitalized COVID-19 patients, ranging from $7 \%$ to $44 \%[2-4,11-17]$. However, there is no consensus on the overall incidence of cardiac 
injury in these patients. Li et al[18] performed a meta-analysis and attempted to determine the incidence of cardiac injury. However, they only analyzed two studies (179 patients) and presented the overall incidence of cardiac injury at $8 \%(15 / 179)$. Although two other studies with more patients were included, these studies only reported elevated creatine kinase levels, which was not specific for cardiac injury and hence could not represent true incidence.

With more evidence available, we included all of the current studies that reported cardiac injury and determined its incidence in hospitalized COVID-19 patients was $23.2 \%$ from a total of 1637 patients (380/1637). Moreover, we performed subgroup analyses and discovered a significantly higher incidence of cardiac injury $(58.5 \%, 286 / 489)$ in patient with poor outcomes (death, ICU admission or critically ill). Although not included in our pooled analysis, Du et al's[8] investigation of 85 fatal cases reported that the incidence of cardiac injury in patient who died from COVID-19 was $44.7 \%(38 / 85)$. This was in stark contrast with patients who were not in the poor outcomes group as their incidence of cardiac injury was only $8.3 \%(95 / 1148)$. Although it can be expected that the incidence of cardiac injury would be higher in patients who were sicker, this marked difference requires more attention in our current battle with COVID19. We believe the overall incidence rate presented in this pooled analysis is more representative due to the larger number of patients included.

\section{Demographics and co-morbidities associated with cardiac injury}

Age is perhaps the most talked about indicators of patient outcomes in this current COVID-19 outbreak as the general public often has the notion that this is a disease of the elderly. Whether there is a connection between age and the development of cardiac injury was also studied. Here, our pooled analysis was consistent with other studies that COVID-19 patients who developed cardiac injury were significantly older (mean difference $=15.98$ years, $95 \% \mathrm{Cl} 11.80-20.15, \mathrm{P}<0.00001$ ). Besides age, the male gender has also been associated with poor outcomes in COVID-19 patients. A pre-print metaanalysis of 77,932 patients by Wei et al[19] revealed that the male gender had significantly higher risks of developing severe cases $(O R=1.63,95 \% \mathrm{Cl} 1.28-2.06)$ and death $(\mathrm{OR}=1.71,95 \% \mathrm{Cl} 1.51-1.93)$. However, although both Shi et al and Guo et al reported more male patients in the cardiac injury group[3,4], our pooled analysis of these two studies did not achieve statistical significance. Thus, whether male patients are more likely to develop cardiac injury still needs more evidence.

Several studies have looked into cardiovascular co-morbidities in COVID-19 patients. In Li et al's metaanalysis of 6 studies[18], the incidence of HTN, DM and cardio-cerebral vascular diseases were $17.1 \%$ $9.7 \%$ and $16.4 \%$. Chen T. et al[11] reported that hospitalized COVID-19 patients with cardiovascular comorbidities were more likely to develop cardiac complications. In the multivariate analysis carried out by Wang L. et al [20], a history of cardiovascular disease was an independent predictor for death. This was consistent with another multivariate analysis from Chen C. et al [17]. On the other end of the spectrum, Guo et al [3] pointed out that a significant number of patient with these co-morbidities did not progress to 
cardiac injury and had relatively favorable outcomes. According to China CDC Weekly in February[21], $80.9 \%$ of all COVID-19 patients (hospitalized and non-hospitalized) with cardiovascular co-morbidities had only mild symptoms with no mortality, $13.8 \%$ severe symptoms and only $4.7 \%$ critically ill among 44,672 confirmed cases. To determine whether having cardiovascular co-morbidities affected the risk of developing cardiac injury, we looked at the combined effects of 603 patients in Guo et al and Shi et al. Consistent with previous reports, hospitalized COVID-19 patients with history of HTN $(O R=5.13,95 \% \mathrm{Cl}$ $3.41-7.72, \mathrm{P}<0.00001), \mathrm{CAD}(\mathrm{OR}=8.94,95 \% \mathrm{Cl} 3.83-20.87, \mathrm{P}<0.00001), \mathrm{DM}(\mathrm{OR}=3.07,95 \% \mathrm{Cl} 1.64-$ $5.75, \mathrm{P}=0.0004)$ and $\mathrm{COPD}(\mathrm{OR}=6.33,95 \% \mathrm{Cl} 1.44-27.85, \mathrm{P}=0.01)$ were more likely to develop cardiac injury.

In addition to demographics and co-morbidities, we also observed substantially elevated levels of NTproBNP in patients who developed cardiac injury (mean difference $=1113.44,95 \% \mathrm{Cl} 256.94-1969.96, \mathrm{P}$ $=0.01$ ) during their hospitalization. This pointed to one possible explanation of the high mortality rate in patients with cardiac injury: acute decompensated heart failure. In the two case reports mentioned above, both patients developed heart failure and required inotropic support $[9,10]$. Zhou F. et al[14] reported that $23 \%$ of hospitalized COVID-19 patients (44/191) developed heart failure symptoms. This ratio increased to $52 \%$ in those who died (28/54). Guo et al[3] not only reported a positive correlation of TnT levels in COVID-19 patients with NT-proBNP $(\beta=0.613, P<0.001)$, but also showed a dynamic increase of NTproBNP during the hospital course exclusively in patients who eventually died. Together with our analysis, these data proposed a new area of investigation of whether COVID-19 patients with cardiac injury died from heart failure.

\section{Cardiac injury in hospitalized COVID-19 patients predicts poor outcomes and death}

Not only is it important to know the association of cardiac injury with co-morbidities, whether it predicts prognosis is of more value. Some studies included in our review reported positive correlation of elevated cardiac biomarkers in patients who had poor outcomes. Both Shi et al[4] and Chen C. et al[17] performed multivariate regression analysis and both reported that cardiac injury was an independent predictor of mortality. However, in the multivariate analysis performed by Wang L et al[20], cardiac injury was only predictive of fatal outcomes in univariate analysis but failed to achieve significance in multivariate analysis. Lippi et al conducted a preliminary meta-analysis of troponin levels in COVID-19 patients and found that it was increased in COVID-19 patients with severe disease than in those without[22].

In our analysis, we integrated 10 studies to better look into how cardiac injury affected outcomes in hospitalized COVID-19 patients. We discovered that hospitalized COVID-19 patients with cardiac injury had a significantly increased mortality rate compared to those without, with an OR of 21.71 . The mortality rate of hospitalized COVID-19 patients with cardiac injury was found to be $75.1 \%(251 / 334)$. This mortality rate was significantly higher than any mortality rates reported so far. Guo et al[3] described a mortality rate of $69.44 \%$ (25/36) for patients who developed cardiac injury and also had underlying 
cardiovascular diseases and $37.50 \%(6 / 16)$ for those with cardiac injury but without cardiovascular comorbidities. Shi et al[4] reported a mortality rate of $51.2 \%(42 / 82)$ in patients with cardiac injury. This extremely high rate of mortality among patients with cardiac injury is alarming. Revisiting the studies included in our analysis, we discovered that in two studies by Zhou F. et al[14] and Deng et al[12], death rate among patients with cardiac injury were particularly high: $97.0 \%(32 / 33)$ and $98.5 \%(65 / 66)$ respectively. These extreme rates may have skewed the overall mortality rate higher and needed to be considered with caution.

Since only 6 studies associated cardiac injury with mortality, we combined death, ICU admission and those who were critically ill as poor outcomes and investigated whether cardiac injury predicted overall poor prognosis in COVID-19 patients. With the rate of poor outcomes as high as $75.3 \%(286 / 380)$, patients with cardiac injury again had significantly elevated risk of being critically ill, needing ICU admission or even death compared to those without ( $\mathrm{OR}=22.18,95 \% \mathrm{Cl} 11.68-42.10, \mathrm{P}<0.00001)$. It is important to note that these high rates of mortality and poor outcomes were only associated with COVID-19 patients who were hospitalized and cannot be applied to those who do not require hospitalization.

\section{Possible etiology of cardiac injury in COVID-19 patients}

Currently several editorials and review articles have elaborated on the possible etiologies of cardiac injury. The mainstream hypotheses include 1) damage caused by cytokine storm triggered by the virus[18], 2) Type II demand ischemia due to hypoxemia caused by the dominating respiratory failure[23], and 3) direct myocardial injury by viral infiltration[24]. As of now, no evidence was available to substantiate direct viral infiltration of cardiomyocytes. Only a few autopsy reports were available that described pathological involvement of the heart. Xu et a.[25] observed the presence of interstitial mononuclear inflammatory infiltrates in the heart but no substantial tissue damage. Another Chinese pathology report by Yao et al[26] described three patients who died of COVID-19 in Chongqing, China. They observed enlarged and necrotic cardiomyocytes with infiltrative phagocytes and rare CD4+ T cells in all three patients. Again, no virus was detected in the heart. More autopsy results are needed. Although Type II demand ischemia should always be kept in mind in patients with respiratory distress, there is hardly direct evidence pointing towards hypoxemia as the sole cause of cardiac injury. Moreover, in Inciardi et al's [10] case report, the previously healthy 53 year-old female COVID-19 patient did not exhibit any signs and symptoms of pneumonia and had normal chest radiographic findings. It seemed like in her case, cardiac involvement was the only complication from her SARS-CoV-2 infection. This potentially reasoned against hypoxemia and Type II demand ischemia as the main cause of cardiac injury. Currently, the most convincing hypothesis of cardiac injury involves cytokine storm. This has been solidified by Huang et al[2], whose study revealed higher plasma levels of IL2, IL7, IL10, GSCF, IP10, MCP1, MIP1A, and TNFa in COVID-19 patients admitted to the ICU. Our analyses also agreed with this hypothesis by showing significantly elevated inflammatory markers including CRP (mean difference $=6.00,95 \% \mathrm{Cl}$ 4.95-7.06, $\mathrm{P}<0.00001$ ) and procalcitonin (mean difference $=0.18,95 \% \mathrm{Cl} 0.13-0.23, \mathrm{P}<0.00001$ ) in 

or without cardiac injury.

\section{Recommendations for managing hospitalized COVID-19 patients with cardiac injury}

Given the high risk of mortality in hospitalized COVID-19 patients with cardiac injury, the authors recommend early screening with cardiac biomarkers, electrocardiograms, and echocardiograms in patients who are at higher risk of developing cardiac injury. These patients are older and often have history of HTN, DM, CAD, and COPD. We hope early detection with appropriate triage and support would help reduce the incidence of cardiac injury in hospitalized COVID-19 patients and the dangerously high rate of mortality and poor outcomes.

\section{Limitations}

This study is limited in several ways. First, limited number of studies reported cardiac injury in COVID-19 patients. Second, only two studies directly compared hospitalized COVID-19 patients with or without cardiac injury. Moreover, a small number of studies did not define or had different diagnostic criteria of cardiac injury and therefore could not be included in the analysis. Third, most studies reported their continuous variables as median with interquartile range. In order to analyze some of these continuous variables, conversion to median with standard deviation was necessary, which might introduce bias in our results.

\section{Conclusion}

Our meta-analysis revealed that cardiac injury was common in hospitalized COVID-19 patients and its incidence was higher in those who had poor outcomes. The overall mortality of patients with cardiac injury was alarmingly high. Cardiac injury was significantly associated with older age and co-morbidities including HTN, DM, CAD and COPD. Hopefully, early screening, triage and support could help reduce the incidence of cardiac injury in hospitalized COVID-19 and its associated poor outcomes.

\section{References}

1. Coronavirus disease (COVID-19) Pandemic. Available via . https://www.who.int/emergencies/diseases/novel-coronavirus-2019. Accessed April 11, 2020

2. Huang C, Wang Y, Li X et al (2020) Clinical features of patients infected with 2019 novel coronavirus in Wuhan, China. The Lancet 395(10223):497-506. https://doi.org/10.1016/S0140-6736(20)30183-5

3. Guo T, Fan Y, Chen M et al (2020) Cardiovascular Implications of Fatal Outcomes of Patients With Coronavirus Disease 2019 (COVID-19). JAMA cardiology. 
https://doi.org/10.1001/jamacardio.2020.1017

4. Shi S, Qin M, Shen B et al (2020) Association of Cardiac Injury With Mortality in Hospitalized Patients With COVID-19 in Wuhan, China. JAMA cardiology. https://doi.org/10.1001/jamacardio.2020.0950

5. Anonymous National Health Commission of the People's Republic of China. Diagnosis and treatment protocol for novel coronavirus pneumonia (6th edition). . Available via .

www.nhc.gov.cn/yzygj/s7653p/202002/8334a8326dd94d329df351d7da8aefc2.shtml. Accessed April 9, 2020

6. Hozo SP, Djulbegovic B, Hozo I (2005) Estimating the mean and variance from the median, range, and the size of a sample. BMC medical research methodology 5(1):13.

https://doi.org/10.1186/1471-2288-5-13

7. He XW, Lai JS, Cheng J et al (2020) Impact of complicated myocardial injury on the clinical outcome of severe or critically ill COVID-19 patients. Zhonghua xin xue guan bing za zhi 48:E011

8. Du Y, Tu L, Zhu P et al (2020) Clinical Features of 85 Fatal Cases of COVID-19 from Wuhan: A Retrospective Observational Study. American journal of respiratory and critical care medicine. https://doi.org/10.1164/rccm.202003-05430C

9. Hu H, Ma F, Wei X et al (2020) Coronavirus fulminant myocarditis treated with glucocorticoid and human immunoglobulin. European Heart Journal. https://doi.org/10.1093/eurheartj/ehaa190

10. Inciardi RM, Lupi L, Zaccone G et al (2020) Cardiac Involvement in a Patient With Coronavirus Disease 2019 (COVID-19). JAMA cardiology. https://doi.org/10.1001/jamacardio.2020.1096

11. Chen T, Wu D, Chen $\mathrm{H}$ et al (2020) Clinical characteristics of 113 deceased patients with coronavirus disease 2019: retrospective study. BMJ (Clinical research ed.) 368:m1091.

https://doi.org/10.1136/bmj.m1091

12. Deng Y, Liu W, Liu K et al (2020) Clinical characteristics of fatal and recovered cases of coronavirus disease 2019 (COVID-19) in Wuhan, China: a retrospective study. Chinese medical journal:1. https://doi.org/10.1097/CM9.0000000000000824

13. Yang X, Yu Y, Xu J et al (2020) Clinical course and outcomes of critically ill patients with SARS-CoV-2 pneumonia in Wuhan, China: a single-centered, retrospective, observational study. The Lancet Respiratory Medicine. https://doi.org/10.1016/S2213-2600(20)30079-5

14. Zhou F, Yu T, Du R et al (2020) Clinical course and risk factors for mortality of adult inpatients with COVID-19 in Wuhan, China: a retrospective cohort study. The Lancet 395(10229):1054-1062. https://doi.org/10.1016/S0140-6736(20)30566-3

15. Zhou B, She J, Wang $Y$ et al (2020) The Clinical Characteristics of Myocardial injury 1 in Severe and Very Severe Patients with 2019 Novel Coronavirus Disease. Journal of Infection. https://doi.org/10.1016/j.jinf.2020.03.021

16. Wang D, Hu B, Hu C et al (2020) Clinical Characteristics of 138 Hospitalized Patients With 2019 Novel Coronavirus-Infected Pneumonia in Wuhan, China. JAMA 323(11):1061. https://doi.org/10.1001/jama.2020.1585 
17. Chen C, Yan JT, Zhou N et al (2020) Analysis of myocardial injury in patients with COVID-19 and association between concomitant cardiovascular diseases and severity of COVID-19. Zhonghua xin xue guan bing za zhi 48:E008

18. Li B, Yang J, Zhao F et al (2020) Prevalence and impact of cardiovascular metabolic diseases on COVID-19 in China. Clinical research in cardiology : official journal of the German Cardiac Society. https://doi.org/10.1007/s00392-020-01626-9

19. Wei X, Xiao Y, Wang J et al (2020) Sex Differences in Severity and Mortality Among Patients With COVID-19: Evidence from Pooled Literature Analysis and Insights from Integrated Bioinformatic Analysis. https://arxiv.org/abs/2003.13547

20. Wang L, He W, Yu X et al (2020) Coronavirus Disease 2019 in elderly patients: characteristics and prognostic factors based on 4-week follow-up. Journal of Infection.

https://doi.org/10.1016/j.jinf.2020.03.019

21. The Novel Coronavirus Pneumonia Emergency Response Epidemiology Team Vital Surveillances: The Epidemiological Characteristics of an Outbreak of 2019 Novel Coronavirus Diseases (COVID-19) - China, 2020. Available via . http://weekly.chinacdc.cn/en/article/id/e53946e2-c6c4-41e9-9a9bfea8db1a8f51. Accessed April 9, 2020

22. Lippi G, Lavie CJ, Sanchis-Gomar F (2020) Cardiac troponin I in patients with coronavirus disease 2019 (COVID-19): Evidence from a meta-analysis. Progress in Cardiovascular Diseases. https://doi.org/10.1016/j.pcad.2020.03.001

23. Driggin E, Madhavan MV, Bikdeli B et al (2020) Cardiovascular Considerations for Patients, Health Care Workers, and Health Systems During the Coronavirus Disease 2019 (COVID-19) Pandemic. Journal of the American College of Cardiology. https://doi.org/10.1016/j.jacc.2020.03.031

24. Wei ZY, Qian HY (2020) Myocardial injury in patients with COVID-19 pneumonia. Zhonghua xin xue guan bing za zhi 48:E006

25. Xu Z, Shi L, Wang Y et al (2020) Pathological findings of COVID-19 associated with acute respiratory distress syndrome. The Lancet Respiratory Medicine 8(4):420-422. https://doi.org/10.1016/S22132600(20)30076-X

26. Yao XH, Li TY, He ZC et al (2020) A pathological report of three COVID-19 cases by minimally invasive autopsies. Zhonghua bing li xue za zhi = Chinese journal of pathology 49:E009

\section{Table 1}

Table 1 Summary of Studies Included 


\begin{tabular}{|c|c|c|c|c|c|c|c|}
\hline Authors & Year & Hospital & Type & $\begin{array}{l}\text { COVID-19 } \\
\text { Patient } \\
\text { Selection }\end{array}$ & $\begin{array}{l}\text { Number } \\
\text { of } \\
\text { Patients }\end{array}$ & $\begin{array}{l}\text { Number } \\
\text { of } \\
\text { Cardiac } \\
\text { Injury }\end{array}$ & Death \\
\hline $\begin{array}{l}\text { Chen T. } \\
\text { et al }{ }^{11}\end{array}$ & 2020 & Tongji Hospital Wuhan & Retrospective & $\begin{array}{l}1 / 13 / 2020 \text { to } \\
2 / 12 / 2020 ; \text { all } \\
\text { deceased or } \\
\text { discharged } \\
\text { patients }\end{array}$ & 274 & 89 & 113 \\
\hline $\begin{array}{l}\text { Deng et } \\
\mathrm{al}^{12}\end{array}$ & 2020 & $\begin{array}{l}\text { Hankou and Caidian } \\
\text { branch of Tongji Hospital } \\
\text { (and) Hankou branch of } \\
\text { Central Hospital of } \\
\text { Wuhan }\end{array}$ & Retrospective & $\begin{array}{l}1 / 1 / 2020 \text { to } \\
2 / 21 / 2020 ; \text { all } \\
\text { deceased or } \\
\text { discharged } \\
\text { patients }\end{array}$ & 225 & 66 & 109 \\
\hline $\begin{array}{l}\text { Yang et } \\
\mathrm{al}^{13}\end{array}$ & 2020 & $\begin{array}{l}\text { Jin Yin-Tan Hospital } \\
\text { Wuhan }\end{array}$ & Retrospective & $\begin{array}{l}12 / 24 / 2019 \text { to } \\
1 / 26 / 2020 ; \text { All } \\
\text { critically ill } \\
\text { patients }\end{array}$ & 52 & 12 & 32 \\
\hline $\begin{array}{l}\text { Zhou F. } \\
\text { et al }\end{array}$ & 2020 & $\begin{array}{l}\text { Jin Yin-Tan Hospital } \\
\text { Wuhan (and) Wuhan } \\
\text { Pulmonary Hospital }\end{array}$ & Retrospective & $\begin{array}{l}12 / 29 / 2019 \text { to } \\
1 / 31 / 2020 ; \text { all } \\
\text { discharged or } \\
\text { deceased } \\
\text { patients }\end{array}$ & 191 & 33 & 54 \\
\hline $\begin{array}{l}\text { Guo et } \\
\mathrm{al}^{3}\end{array}$ & 2020 & $\begin{array}{l}\text { Seventh Hospital of } \\
\text { Wuhan City }\end{array}$ & Retrospective & $\begin{array}{l}1 / 23 / 2020 \text { to } \\
2 / 23 / 2020 \text { all } \\
\text { patients }\end{array}$ & 187 & 52 & 43 \\
\hline $\begin{array}{l}\text { Shi et } \\
\mathrm{al}^{4}\end{array}$ & 2020 & $\begin{array}{l}\text { Renmin Hospital of } \\
\text { Wuhan University }\end{array}$ & Retrospective & $\begin{array}{l}1 / 20 / 2020 \text { to } \\
2 / 10 / 2020 ; \text { all } \\
\text { patients }\end{array}$ & 416 & 82 & 57 \\
\hline $\begin{array}{l}\text { Huang } \\
\text { et } \mathrm{al}^{2}\end{array}$ & 2020 & $\begin{array}{l}\text { Jin Yin-Tan Hospital } \\
\text { Wuhan }\end{array}$ & Prospective & $\begin{array}{l}12 / 16 / 2019 \text { to } \\
1 / 2 / 2020 ; \text { all } \\
\text { patients }\end{array}$ & 41 & 5 & 6 \\
\hline $\begin{array}{l}\text { Wang } \\
\text { et } \mathrm{al}^{16}\end{array}$ & 2020 & $\begin{array}{l}\text { Zhongnan Hospital of } \\
\text { Wuhan University }\end{array}$ & Retrospective & $\begin{array}{l}1 / 1 / 2020 \text { to } \\
1 / 28 / 2020 ; \text { all } \\
\text { patients }\end{array}$ & 138 & 10 & 6 \\
\hline $\begin{array}{l}\text { Chen } \\
\text { C. et } \\
\mathrm{al}^{17}\end{array}$ & 2020 & $\begin{array}{l}\text { Hankou, Zhongfa Xin } \\
\text { Cheng and Guang Gu } \\
\text { branches of Tongji } \\
\text { Hospital }\end{array}$ & Retrospective & $\begin{array}{l}1 / 2020 \text { to } \\
2 / 2020 ; \text { all } \\
\text { patients }\end{array}$ & 150 & $22 *$ & 11 \\
\hline $\begin{array}{l}\text { Zhou B. } \\
\text { et al }^{15}\end{array}$ & 2020 & $\begin{array}{l}\text { West District of Union } \\
\text { Hospital of Tongji } \\
\text { Medical College }\end{array}$ & Retrospective & $\begin{array}{l}2 / 5 / 2020 \text { to } \\
2 / 132020 \text {, all } \\
\text { patients }\end{array}$ & 34 & 9* & $\begin{array}{l}\text { Not } \\
\text { reported }\end{array}$ \\
\hline
\end{tabular}

\section{Figures}




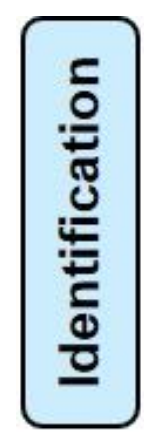

Records identified in PubMed and Embase $(n=2413)$
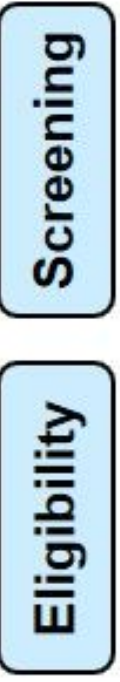

웡

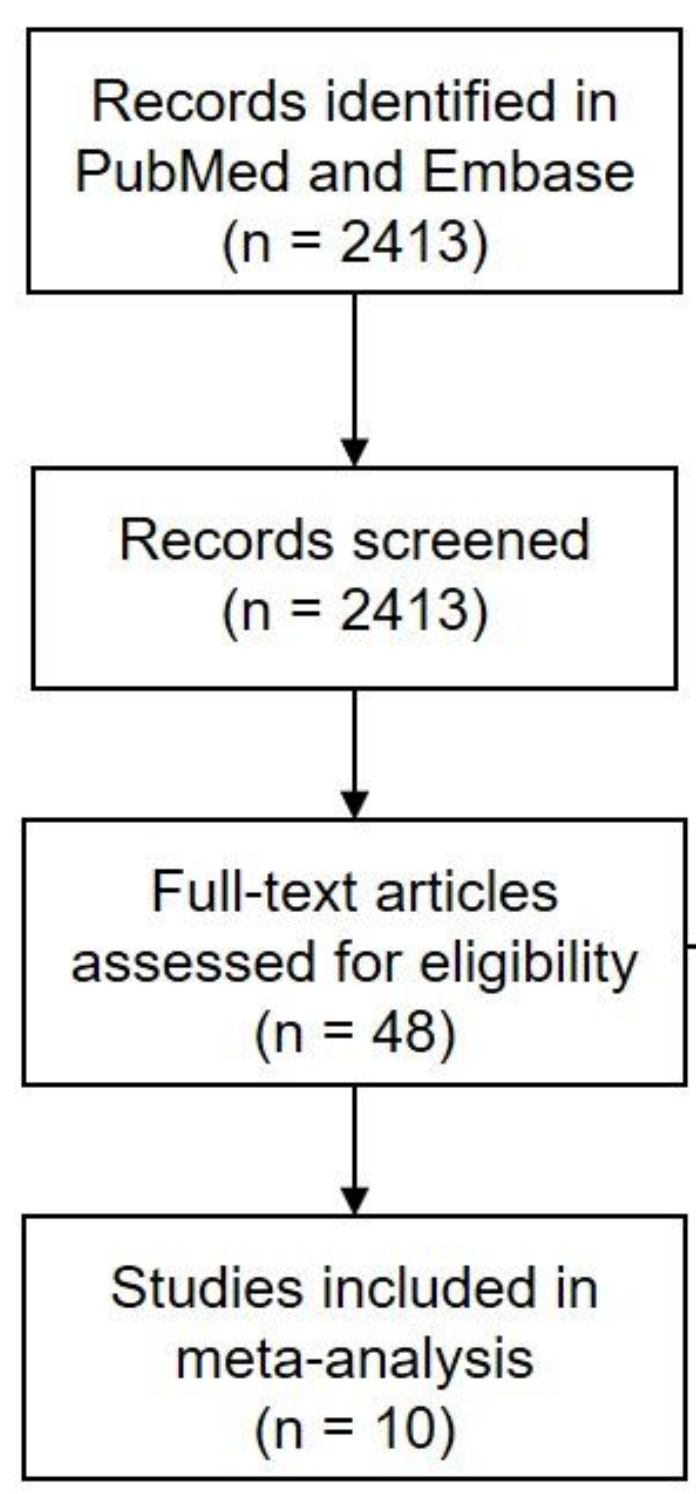

Full-text articles excluded - Review articles and metaanalyses: 11

- Case reports/series: 4 -Did not report troponin or CKMB: 18

-Duplicate patients: 3

-Different definition of cardiac injury: 1

- Only reported deceased patients: 1

Figure 1

Flowchart of Study Selection Process 
A

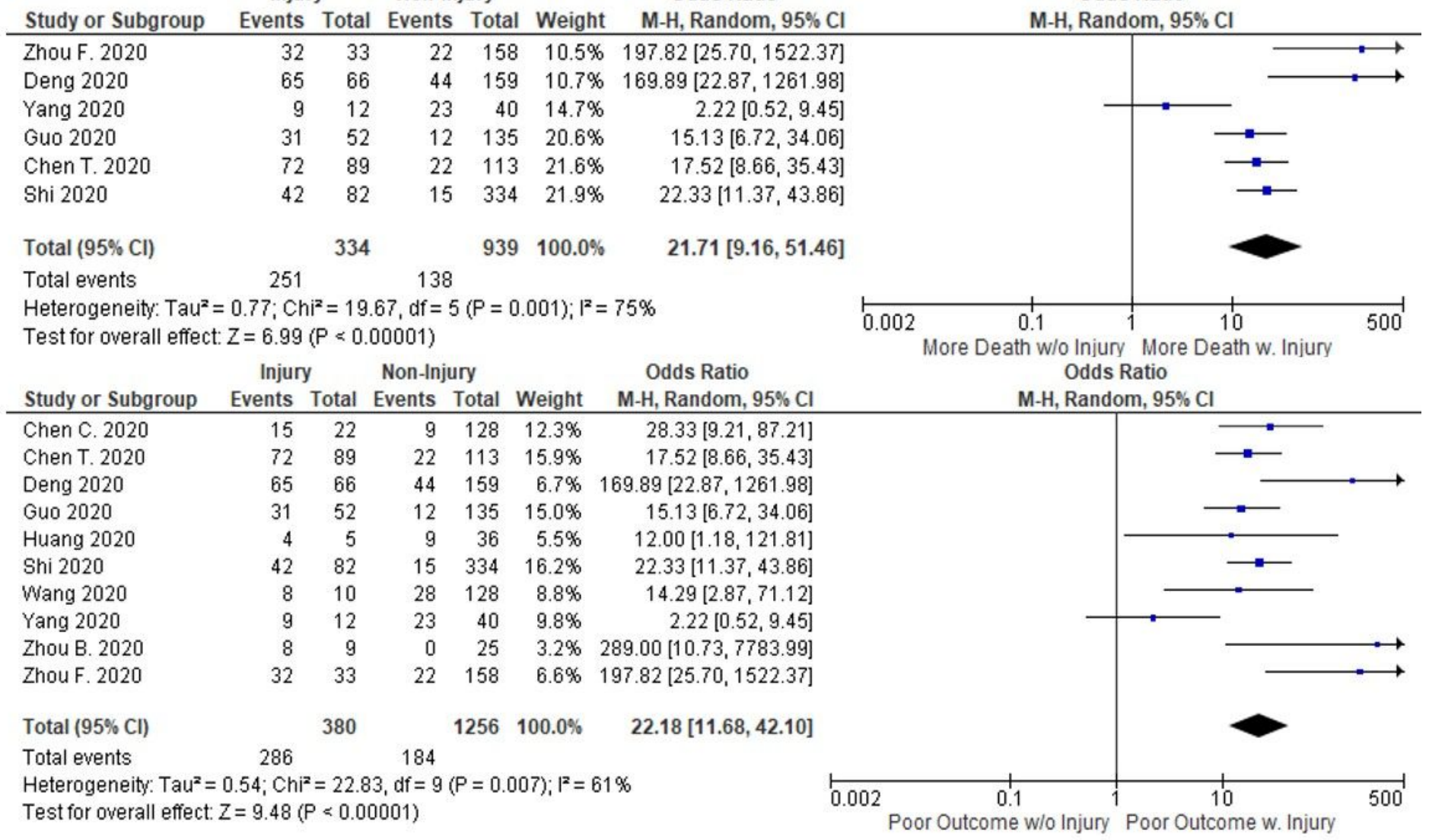

Figure 2

Comparison of Mortality and Poor Outcomes in Hospitalized COVID-19 Patients With or Without Cardiac Injury. A) Cardiac injury and mortality; B) Cardiac injury and poor outcomes (combined death, ICU admission and critically ill). Hospitalized COVID-19 patient with cardiac injury had significantly higher rates of mortality and poor outcomes compared to those without 


\begin{tabular}{|c|c|c|c|c|c|c|c|c|}
\hline & & \multicolumn{2}{|c|}{ Injury } & \multicolumn{3}{|c|}{ No injury } & \multicolumn{2}{|r|}{ Mean Differe } \\
\hline \multirow{3}{*}{ A } & Study or Subgroup & Mean & SD To & tal Mea & in $\quad S D$ & Total & Weight & IV, Random, \\
\hline & Guo 2020 & $71.4 \quad 9$ & 9.43 & $52 \quad 53.1$ & 13.22 & 135 & $46.3 \%$ & $18.27[14.87$ \\
\hline & Shi 2020 & 7410 & 10.17 & $82 \quad 6$ & 11.5 & 334 & $53.7 \%$ & $14.00[11.4$ \\
\hline \multirow{9}{*}{$B$} & Total $(95 \% \mathrm{Cl})$ & & & 134 & & 469 & $100.0 \%$ & $15.98[11.8$ \\
\hline & \multicolumn{8}{|c|}{$\begin{array}{l}\text { Heterogeneity: } \text { Tau }^{2}=6.79 ; \mathrm{Chi}^{2}=3.91, \mathrm{df}=1(P=0.05) ; \mathrm{I}^{2}=74 \% \\
\text { Test for overall effect: } Z=7.50(P<0.00001)\end{array}$} \\
\hline & & \multicolumn{2}{|c|}{ Female } & \multicolumn{2}{|c|}{ Male } & & \multicolumn{2}{|c|}{ Odds Ratio } \\
\hline & Study or Subgroup & Events & Total & Events & Total & Weight & M-H, R & Random, 95 \\
\hline & Guo 2020 & 18 & 96 & 34 & 91 & $44.9 \%$ & & $0.39[0.20,0$ \\
\hline & Shi 2020 & 38 & 211 & 44 & 205 & $55.1 \%$ & & $0.80[0.50,1$ \\
\hline & Total $(95 \% \mathrm{Cl})$ & & 307 & & 296 & $100.0 \%$ & & $.58[0.28,1$ \\
\hline & Total events & 56 & & 78 & & & & \\
\hline & $\begin{array}{l}\text { Heterogeneity. Tau } \\
\text { Test for owerall effec }\end{array}$ & $\begin{array}{l}=0.18 ; \mathrm{Chi}^{-} \\
\mathrm{Z}=1.50(\end{array}$ & $\begin{array}{l}z=3.03 \\
P=0.1\end{array}$ & $\begin{array}{l}\text { 3. } d f=1( \\
3)\end{array}$ & $(P=0.08$ & 8); $1^{2}=67$ & & \\
\hline
\end{tabular}

With HTN W/O HTN
C

\begin{tabular}{lrrrrr} 
Guo 2020 & 33 & 66 & 19 & 126 & $35.5 \%$ \\
\hline
\end{tabular}
Shi 2020
Total $(95 \% \mathrm{Cl})$
Total events
82
193
Heterogeneity: $\operatorname{Tau}^{2}=0.00 ; \mathrm{Chi}^{2}=0.11, \mathrm{df}=1(\mathrm{P}=0.74) ; \mathrm{I}^{2}=0 \%$
Test for overall effect: $Z=7.84(P<0.00001)$

With CAD W/o CAD

Study or Subgroup Events Total Events Total Weight M-H, Random, 95\% Cl

$\begin{array}{lllllll}\text { Guo } 2020 & 17 & 21 & 35 & 166 & 35.7 \% & 15.91 \\ {[5.03,50.30]}\end{array}$

Shi 2020

$24 \quad 44$

$58 \quad 372 \quad 64.3 \%$

$6.50[3.37,12.52]$

Total $(95 \% \mathrm{Cl})$

Total events

65

41

93

$538 \quad 100.0 \%$

$8.94[3.83,20.87]$

Test for overall effect: $Z=5.07(P<0.00001)$

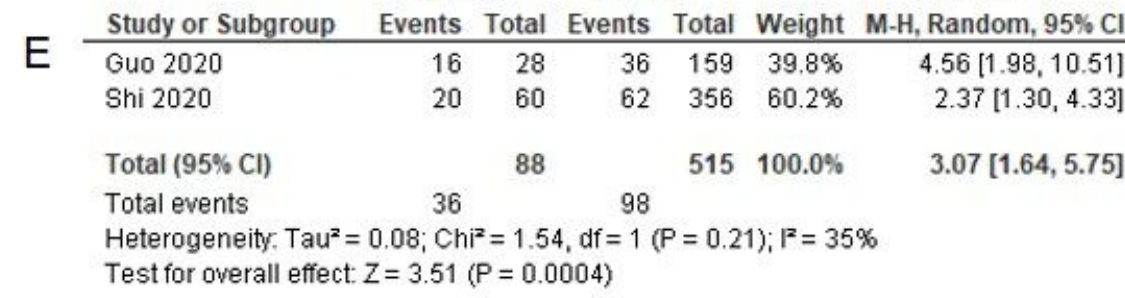

Heterogeneity, $\mathrm{Tau}^{2}=0.08 ; \mathrm{Chi}^{2}=1.54, \mathrm{df}=1(\mathrm{P}=0.21) ; \mathrm{I}^{2}=35 \%$

Test for overall effect: $Z=3.51(P=0.0004)$

Odds Ratio
, Random, $95 \% \mathrm{Cl}$

$5.63[2.84,11.19]$

$4.87[2.93,8.11]$

$5.13[3.41,7.72]$
Heterogeneity: $\operatorname{Tau}^{2}=0.18 ; \mathrm{Chi}^{2}=1.78, \mathrm{df}=1(\mathrm{P}=0.18) ; \mathrm{I}^{2}=44 \%$

With DM W/o DM

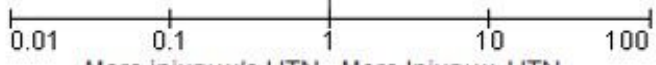

More injury w/o HTN More Injury w. HTN

Odds Ratio

M-H, Random, $95 \% \mathrm{Cl}$

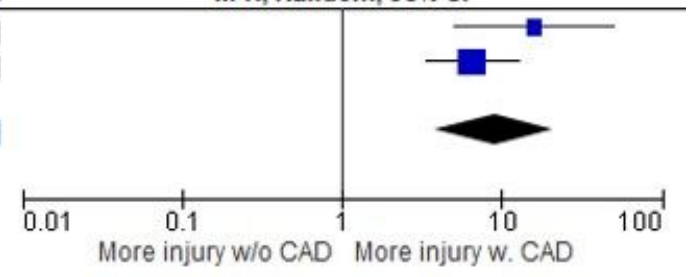

Odds Ratio

M-H, Random, $95 \% \mathrm{Cl}$

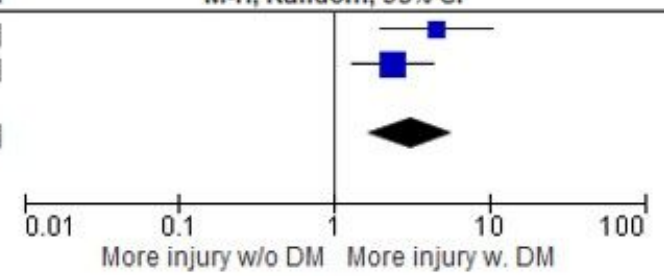

Odds Ratio

M-H, Random, $95 \% \mathrm{Cl}$

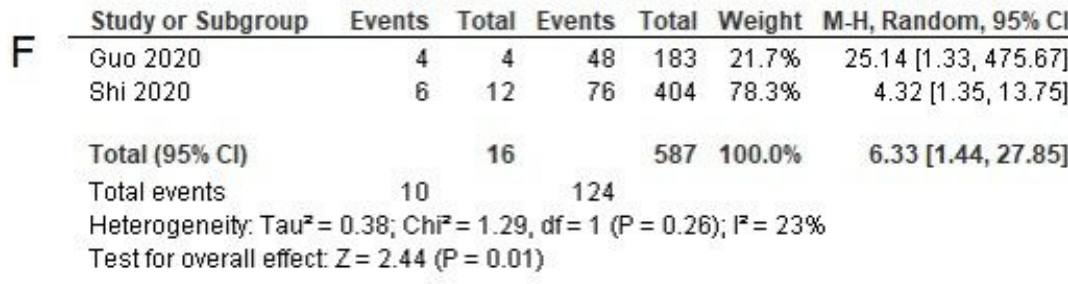

Test for overall effect: $Z=2.44(P=0.01)$

\section{Figure 3}

Comparison of Demographics and Co-morbidities in Hospitalized COVID-19 Patients With or Without Cardiac Injury. A) Age; B) Gender; C) Hypertension (HTN); D) Coronary artery disease (CAD); E) Diabetes (DM); F) Chronic Obstructive Pulmonary Diseases (COPD). COVID-19 patients who were older and had history of HTN, CAD, DM and COPD exhibited increased odds of developing cardiac injury during hospitalization. The effect of gender on cardiac injury did not reach statistical significance 


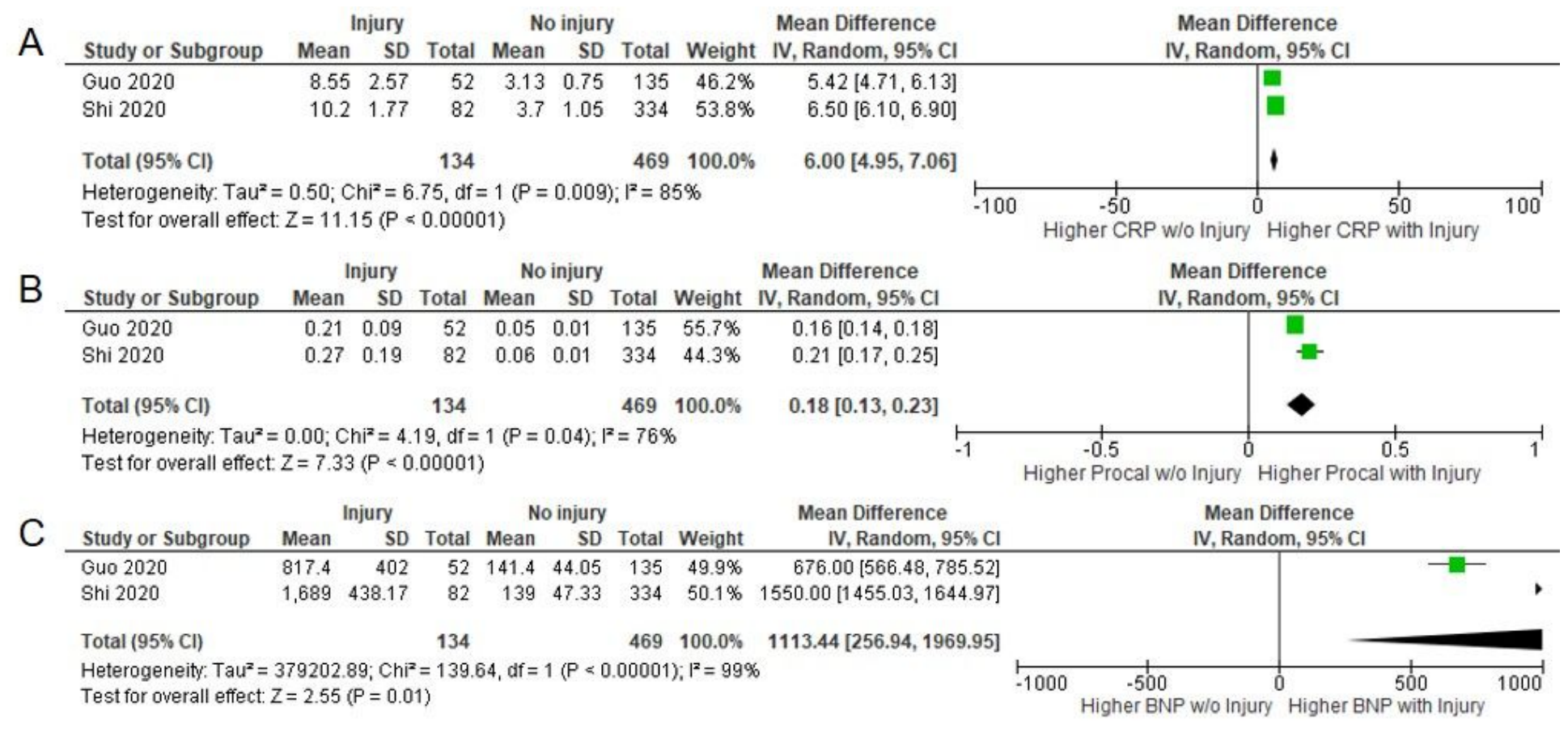

\section{Figure 4}

Comparison of Laboratory Values in Hospitalized COVID-19 Patients With or Without Cardiac Injury. A) Creactive protein (CRP); B) Procalcitonin (Procal); C) NT-pro brain natriuretic peptide (NT-proBNP).

Hospitalized COVID-19 patients with cardiac injury had significantly increased CRP, procalcitonin and NTproBNP compared to those without

\section{Supplementary Files}

This is a list of supplementary files associated with this preprint. Click to download.

- Supplementallnformation.docx 